\title{
Development of Strength Model of Lateritic Soil-Cement
}

\author{
Saravut Jaritngam*, William O. Yandell, and Pichai Taneerananon \\ Department of Civil Engineering, Prince of Songkla University, Hatyai, Songkhla, Thailand \\ *E-mail: jaritngam@gmail.com (Corresponding author)
}

\begin{abstract}
Since the shortage of crushed rock as base course in some regions of Thailand, the improvement of the lateritic soil-cement as pavement base course has been evaluated. Soil cement improvement has been used for many years because of the significant improvement in soil properties. The objective of the research effort is to investigate performance of Lateritic soil cement mixtures using experimental study. The experimental results in terms of unconfined compressive strength and elasticity modulus were improved significantly as the cement content is increased. The multiple regression models based on cement content and curing time parameters were proposed to predict the unconfined strength (UCS) and elastic modulus of Lateritic soil-cement. The proposed prediction models providing good correlations with the experimental data are presented in this study.
\end{abstract}

Keywords: Lateritic, soil, cement, pavement, materials, multiple regression.

ENGINEERING JOURNAL Volume 17 Issue 1

Received 26 May 2012

Accepted 8 July 2012

Published 1 January 2013

Online at http://www.engj.org/

DOI:10.4186/ej.2013.17.1.69 


\section{Introduction}

Lateritic soil is one of local materials extensively formed in the southern of Thailand. In general, the strength of lateritic soil excavated from the upper profile is quite low. However, the strength of lateritic soil will increase significantly by stabilizing with low contents of cement. Thus, the lateritic soil stabilized with cement can be widely utilized as a low-cost pavement base of roads particularly in available areas of lateritic soil. Soil stabilization with original Portland cement is one of various soil improvement methods in road geotechnical engineering. This technique has been economical compared with other soil improvement methods.

The cement stabilized base is produced by mixing In-situ cement with lateritic soil to improve shear strength and elastic modulus. The shear strength of soil samples can be experimentally evaluated using unconfined compression tests. The upper limit of unconfined compressive strength of $2000 \mathrm{kPa}(20.13 \mathrm{ksc})$ after 7 days cured was introduced to prevent the excessive use of cement [1]. In addition, many soil cement samples collected from existing roads and prepared in laboratory were test. Unconfined compressive strength of the cored samples is far beyond the design unconfined compressive strength at 7 days cured $(1724 \mathrm{kPa}$ or $17.5 \mathrm{ksc})$. Surface crack highways on soil cement base with highway crack seal and chip seal maintenances were performed very well [2-4].

The chief factors affecting the quality of soil-cement are content of $\mathrm{SO}_{3}, \mathrm{pH}$, salt content, soil type, cement content, compaction and method of mixing. Of these the soil type is by far the most important factor since, if it is unsuitable, little can be done to make the soil-cement satisfactory. If the content of $\mathrm{SO}_{3}$ in the soil is greater than $0.2 \%$ or $\mathrm{SO}_{4}$ content is greater than $0.5 \%$, or if the $\mathrm{SO}_{3}$ content in the groundwater exceeds $300 \mathrm{mg} / \mathrm{l}$, the strength of the cement mix will be reduced [5, 6]. Anon reports that soils with $\mathrm{pH}$ values of less than 5 are unsuitable for economic stabilization [7]. Kawasaki et al. points out that the stabilization effect will greatly deteriorate, when the $\mathrm{pH}$ value drops below 5 [8]. A soil with low $\mathrm{pH}$ is usually associated with high organic content. This type of soil is unsuitable for cement treatment. There is very little gain in strength even mixing with large quantities of cement. High salt content, especially sulphates, can retard hydration of cement in soil-cement mixtures [7]. Greater strength is obtained if distilled water is used rather than sea water. Results have shown that strength will be as much as $30 \%$ lower when using sea water [9].

In terms of effectiveness of cement treatment, Winterkorn and Fang divide the soil into three groups [10]: 1) Sandy and gravely soils with 10-35\% silt and clay content. This group of soil can be easily pulverized and mixed and used under a wide range of weather conditions. These soils usually require the least amount of cement for adequate hardening. 2) Sandy soils deficient in fines. This group of soil requires a slightly more cement content than the soils in the first group for comparable results in hardening. 3) Silty and clayey soils. This group of soil can produce a satisfactory soil-cement mix. Those with high clay content are difficult to pulverize and may result in a product that has excessive shrinkage properties. Weather conditions affect this group more than the previous two groups, whose granular skeletons are not affected by moisture content.

The unconfined compressive strength of the treated soil may be as low as $1,380 \mathrm{kPa}$ for fine-grained soils with $16 \%$ cement and more than 10,000 $\mathrm{kPa}$ for granular soil-cement with $3 \%$ cement [11]. Bell found that granular soils mix more easily than fined-grained soils and they require less cement [12]. The individual grains are coated with cement paste and bonded at their points of contact as the grain size of granular soils is larger than that of cement. Anon pointed out that the cement requirements for various soil types are quite different [7]. Under the same curing conditions, soils with higher cement content will be stronger than soils with lower cement content. Bergado et al. shows that the strength is a direct function of cement content [13]. Mitchell suggested that for fine grained soil the unconfined compressive strength (UCS) is a linear function of cement content [11].

\section{Methodology}

Before starting sample preparation, the moisture density relationship was determined and prepared for each cement content. The cement used in the study was ordinary Portland cement (OPC or Type I). Compaction was achieved by the modified Proctor procedure (ASTM D-1557). The cement content used in this investigation was $3 \%, 5 \%, 7 \%$ and $9 \%$ with respect to the dry weight of the lateritic soil to investigate the 
methods in stabilizing lateritic soil samples. The effect of cement content, curing time and unit weight on the strength and stiffness characteristics of the lateritic soil-cement mix has been investigated.

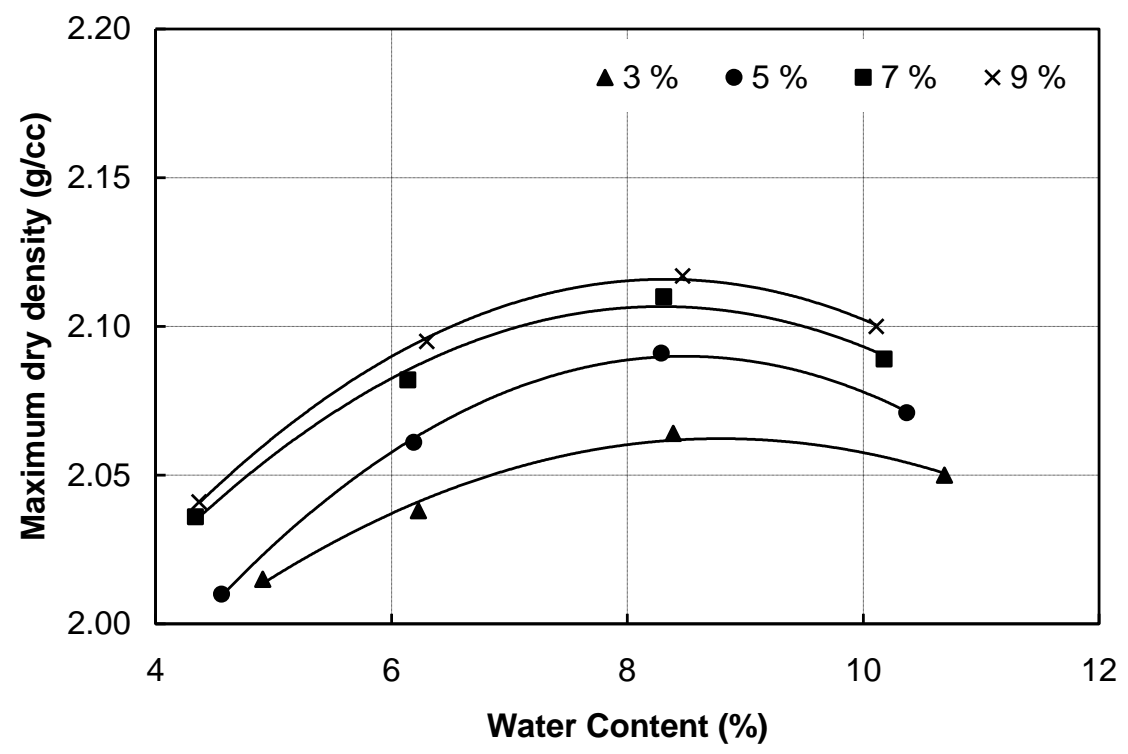

Fig. 1. The water content-density relationship of cement stabilized.

As shown in Fig. 1, there is no significant change in the optimum water content of the lateritic soilcement mixtures with the increase in cement content. A compaction test is to re-arrange soil particles. Soil can reach it maximum dry density by wetting and re-arrange the soil particles by water molecules and compaction. For these soils with cement mixtures, the maximum dry density is between 2.06 and 2.12 $\mathrm{g} / \mathrm{cm}^{3}$. The optimum water content is between $8.2 \%$ and $8.4 \%$ for different amounts of cement added to soil. Therefore, the peaks of each compaction curves for different cements are recommended to improve the interlocking force among soil particles.

Firstly, mixed lateritic soil with cement according to design mixing ratio by hand for about 15 minutes and admixed them with water at amount of optimum water content according to Fig. 1. Each specimen was prepared using cylindrical mold having inner diameter of $101.6 \mathrm{~mm}$ and height of $116.8 \mathrm{~mm}$. The prepared soil was placed in the cylindrical mold in five layers and each layer was compacted according to the procedure of modified Proctor compaction. After compaction, the specimens were wrapped with plastic sheet and cured at room temperature of about $28^{\circ} \mathrm{C}$ and submerged under water for 2 hours before testing. Unconfined compression tests were conducted at the curing time, which are summarized in Table 1 . The increase of the shear strength of the stabilized soil was determined after 3, 7, 14 and 28 days after the mixing. Laboratory tests were conducted to access the strength and stiffness of the lateritic soil-cement mixture. The statistical method was adopted to evaluate the sensitivity of various factors.

Table 1. Details of test series.

\begin{tabular}{lrccr}
\hline \multirow{2}{*}{ Cement Content (\%) } & \multicolumn{4}{c}{ Curing Times (days) } \\
\cline { 2 - 5 } & $\mathbf{3}$ & $\mathbf{7}$ & $\mathbf{1 4}$ & $\mathbf{2 8}$ \\
\hline 3 & C3T3 & C3T7 & C3T14 & C3T28 \\
5 & C5T3 & C5T7 & C5T14 & C5T28 \\
7 & C7T3 & C7T7 & C7T14 & C7T28 \\
9 & C9T3 & C9T7 & C9T14 & C9T28 \\
\hline
\end{tabular}

\section{Soil Property Test Results}

\subsection{Index Properties}

Lateritic soil was collected from a site at Hatyai in Thailand about 0.5-2.0 $\mathrm{m}$ depth below the ground surface. The lateritic soil was sealed in the air tight plastic containers and transported to the laboratory for 
testing. The soil properties before mixing, such as, sieve analysis, the Atterberg's limit test, water content, unit weight and CBR are shown in Table 2. Table 3 shows the particle size distribution of these soils.

Table 2. Summary of basic properties of the laterite soil sample at Songkhla, Thailand.

\begin{tabular}{ll}
\hline Soil Properties & Value \\
\hline Liquid limit & $50 \%$ \\
Plastic limit & $34.2 \%$ \\
PI & $15.8 \%$ \\
Water content & $26.72 \%$ \\
Unit weight $\left(\right.$ ton $\left./ \mathrm{m}^{3}\right)$ & 2.076 \\
Specific Gravity & 2.69 \\
CBR dry & $118 \%$ \\
Unified Classification & $\mathrm{A}-2-7$ \\
AASHTO Classification & $\mathrm{SC}$ \\
\hline
\end{tabular}

Table 3. Particle size distribution for soil used.

\begin{tabular}{lr}
\hline Sieve & \% passing \\
\hline 2" & 100 \\
1" & 91.7 \\
3/8” & 72.1 \\
$\# 4$ & 51.8 \\
$\# 10$ & 30.1 \\
$\# 40$ & 14.7 \\
$\# 200$ & 10.6 \\
Pan & \\
\hline
\end{tabular}

\section{Soil-Cement Mixing Test Results}

Results of all tests are summarized in Table 4. Some failure mechanisms of the tested samples are shown in Fig. 2. It also revealed that more brittle type of failure were observed with curing period of 7 days.

Table 4. Results of test series.

\begin{tabular}{lccccr}
\hline Test \# & C $_{\mathbf{C}}$ & T & D $_{\mathbf{D}}$ & $\mathbf{U C S}$ & $\mathbf{E S}$ \\
\hline C3T3 & 3 & 3 & 2.133 & 18.97 & 3548 \\
C5T3 & 5 & 3 & 2.133 & 34.77 & 6400 \\
C7T3 & 7 & 3 & 2.212 & 51.85 & 9010 \\
C9T3 & 9 & 3 & 2.152 & 61.14 & 12014 \\
C3T7 & 3 & 7 & 2.132 & 22.65 & 4332 \\
C5T7 & 5 & 7 & 2.195 & 39.19 & 6900 \\
C7T7 & 7 & 7 & 2.194 & 54.66 & 9710 \\
C9T7 & 9 & 7 & 2.141 & 66.75 & 12838 \\
C3T14 & 3 & 14 & 2.150 & 24.69 & 4963 \\
C5T14 & 5 & 14 & 2.184 & 45.73 & 8100 \\
C7T14 & 7 & 14 & 2.230 & 61.61 & 11515 \\
C9T14 & 9 & 14 & 2.139 & 73.69 & 14716 \\
C3T28 & 3 & 28 & 2.175 & 34.57 & 6680 \\
C5T28 & 5 & 28 & 2.184 & 54.68 & 9702 \\
C7T28 & 7 & 28 & 2.203 & 69.06 & 12690 \\
C9T28 & 9 & 28 & 2.154 & 83.30 & 15544 \\
\hline
\end{tabular}

Note: $\mathrm{C}_{\mathrm{C}}=$ the cement content, $\mathrm{T}=$ the curing time, $\mathrm{D}_{\mathrm{D}}=$ dry density $\left(\right.$ ton $\left./ \mathrm{m}^{3}\right)$, UCS $=$ unconfined compressive strength (ksc), and $\mathrm{ES}=$ Modulus of elasticity (ksc). 


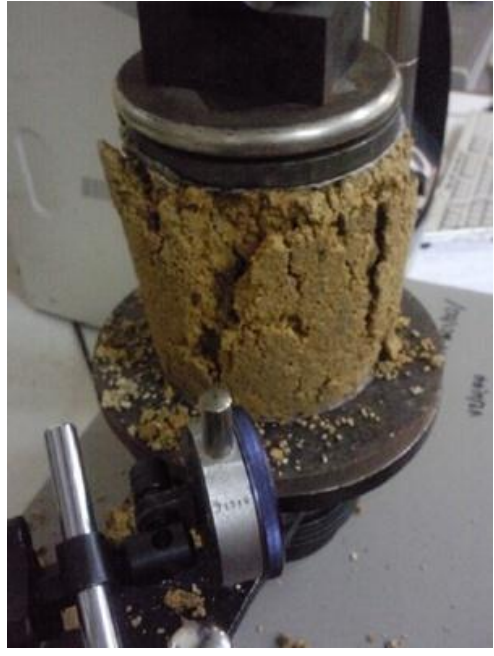

(a) The $3 \%$ cement

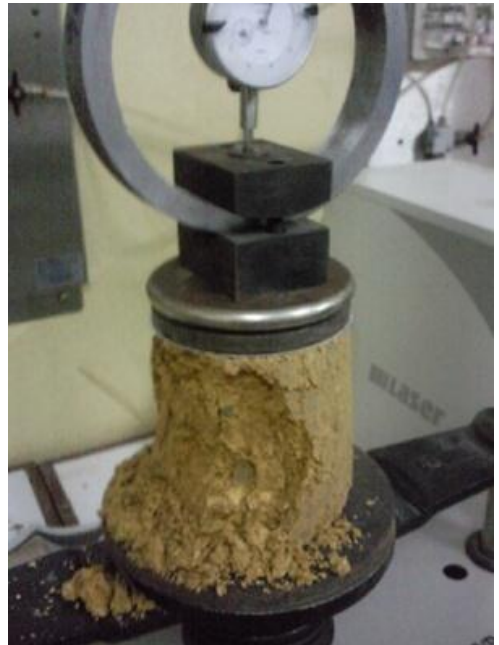

(b) The $5 \%$ cement

Fig. 2. The samples of the $3 \%$ and $5 \%$ cement mixing at 7 days.

\subsection{Effect of Cement Content on Unconfined Compressive Strength}

Typical cement content used in soil stabilization varies from 3\% to $9 \%$. If the lateritic soil-cement is too dry, it is hard to mix evenly and may result in shrinkage cracks; but if it is too wet, it may result in low strength after mixing. The relationship between cement content, time and unconfined compressive strength of the cement treated soil is shown in Fig. 3. The strength increases proportionally with increasing cement content. It appears that the 28 days strength can be estimated using the following equation proposed by Mitchell [11] as shown in Eq. (1). It is evident that predicted values of strength determined by this equation are much higher than the experimental values.

$$
U C S=(300 \text { to } 600) C_{C}
$$

where $\mathrm{C}_{\mathrm{C}}$ is the cement content $(\%)$.

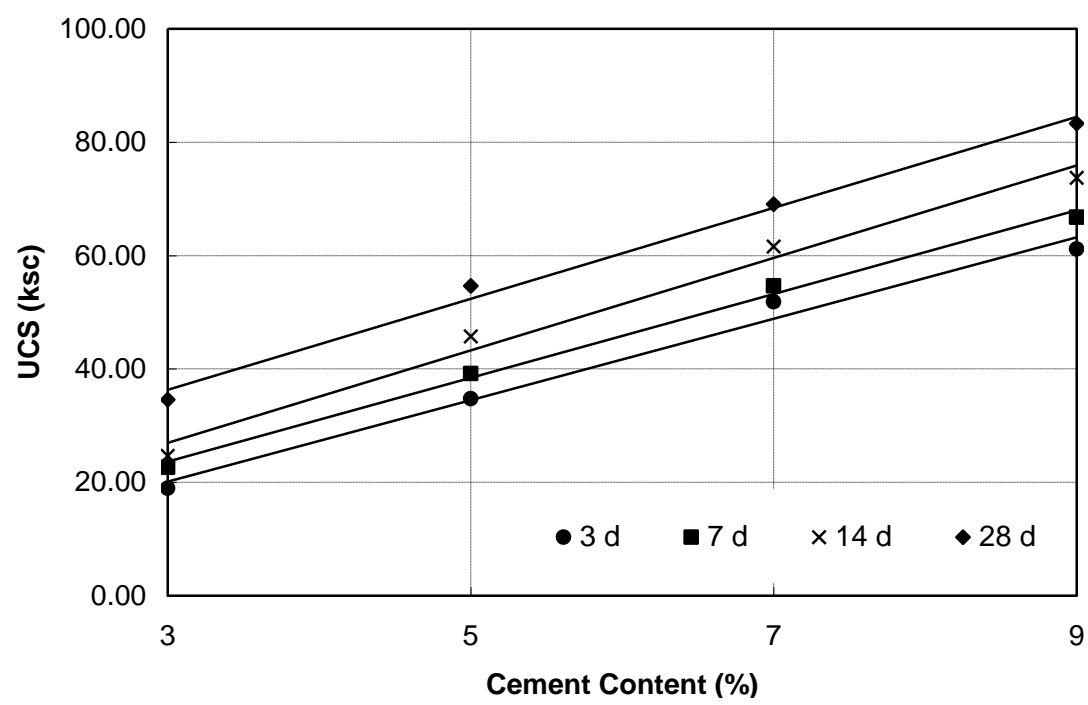

Fig. 3. Effect of cement content and curing time (UC test). 


\subsection{Effect of Curing Time on Strength and Stiffness}

The tests were to investigate the increase of the unconfined compressive strength and the effect of aging on the stabilized soil. Fig. 3 shows the unconfined compressive strength of the cement treated lateritic soil as determined by unconfined compression tests. It can be seen that the compressive strength increased with increasing cement content as well as with increasing time of the curing. It increased to $22.65 \mathrm{ksc}, 39.19 \mathrm{ksc}$, $54.66 \mathrm{ksc}$ and $66.75 \mathrm{ksc}$ after 7 days with $3 \%, 5 \%, 7 \%$ and $9 \%$ cement, respectively. The increase of the compressive strength was thus large when the cement content was high.

The mix contained 3\% cement, 7 and 28 days unconfined compressive strength test samples gave strength of $22.65 \mathrm{ksc}$ and $39.19 \mathrm{ksc}$, respectively. It was also noted that laboratory prepared samples produce a 7 days strength over $17.5 \mathrm{ksc}$ following specification of Highway Department for base course materials. The initial increase of the compressive strength of the cement treated soil was mainly caused by a reduction of the water content due to hydration. The increase of the compressive strength was still large even after 28 days due to ion exchange and cementation. It can be seen that the effect of the cementation increases rapidly with increases with time for the cement treated lateritic soil. The increases of the compressive strength due to a reduction of the water content are proportional to the cement content. It was observed that the reduction of the water content decreased with time. The reduction of the water content contributed substantially to the short term improvement of the compressive strength while the long term improvement was mainly caused by cementation.

Using the 3 days strength as a reference, the strength at 7 days varies from 1.11 to 1.17 of the 3 days strength with an average value of 1.14. The strength at 14 days varies from 1.11 to 1.17 of the strength at 7 days with an average value of 1.14. The strength at 28 days varies from 1.07 to 1.19 of the strength at 14 days with an average value of 1.13 . Results show that the optimum curing time for all specimens is 14 days. The variation of strength with curing time is shown in Fig. 4.

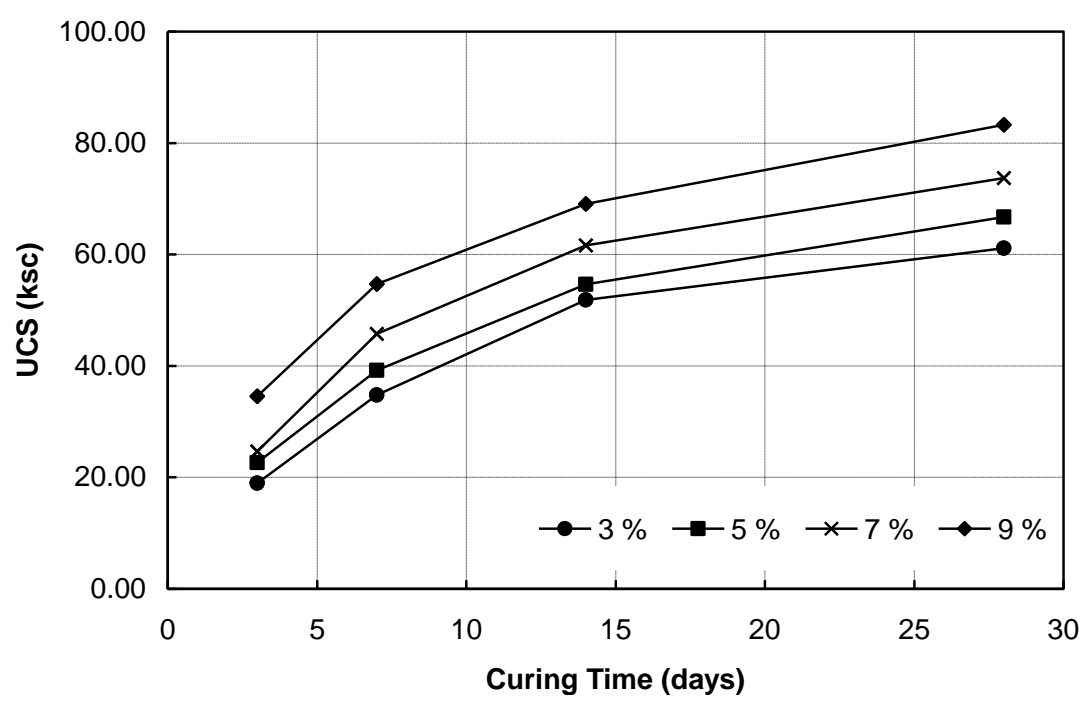

Fig. 4. The variation of strength with curing time.

The initial increase of the unconfined compressive strength of the cement treated soil was mainly caused by a reduction of the water content due to hydration. The increase of the compressive strength was still large even after 28 days due to ion exchange and cementation. Figure 4 illustrates the relative improvement of the compressive strength with cement. It can be seen that the effect of the cementation increases rapidly with increases with time for the cement treated lateritic soil. The increases of the compressive strength due to a reduction of the water content are proportional to the cement content. It was observed that the reduction of the water content decreased with time. The reduction of the water content contributed substantially to the short term improvement of the compressive strength while the long term improvement was mainly caused by cementation. The strength varies linearly with the logarithmic time as can be seen in Fig. 5. 


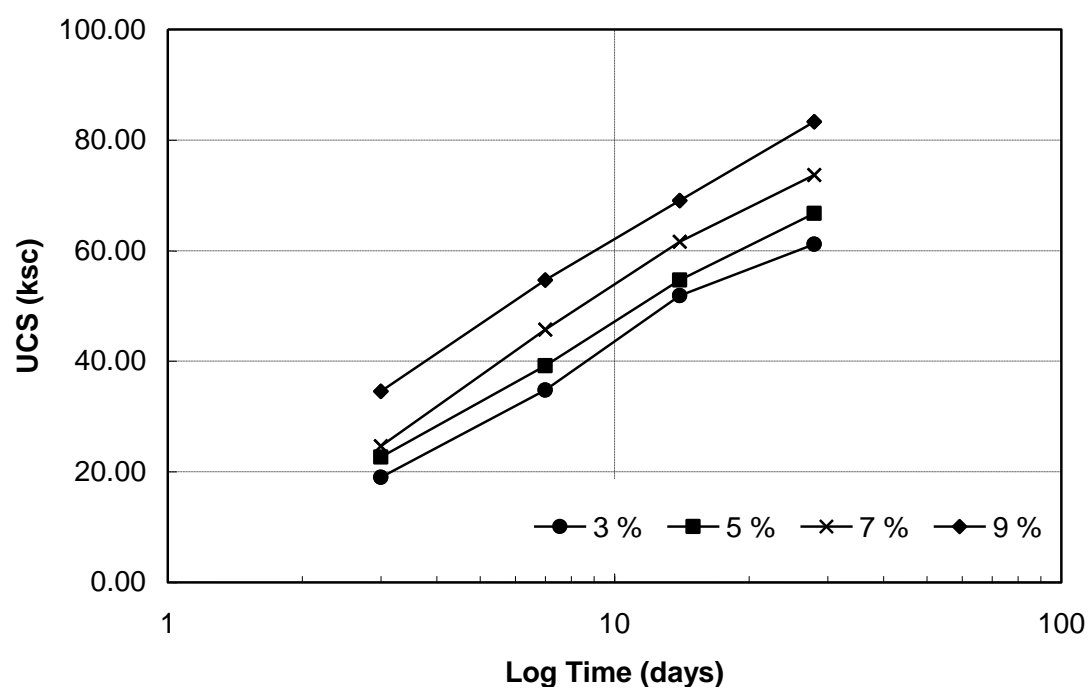

Fig. 5. The strength varies linearly with the logarithmic time.

\section{Analysis}

From experimental data, the results for soil-cement mixing are presented in Table 4. The experimental results with 16 tests represent the unconfined compressive strength and modulus of elasticity during the 28 days after addition of water. The cement content $\left(C_{C}\right)$, curing time $(T)$ and dry density $\left(D_{D}\right)$ are linearly dependent predictors of the cement content, the curing time and the dry density of soil. Variable (UCS) and (ES) are the unconfined compressive strength and the modulus of elasticity, respectively. The multiple regression model [14] was proven to have a good fit with inclusion of all the two predictors (UCS and ES) presented as given in Eq. (2).

$$
y_{i}=\beta_{0}+\beta_{1} x_{i 1}+\beta_{2} x_{i 2}+\beta_{3} x_{i 3}, i=1,2, \ldots, n
$$

where, $y_{i}$ is the predictors (UCS and ES), $\beta_{i}$ is numerical constants and $x_{i i}$ is soil cement parameters. In this model, multiple regression analysis is applied to all data. The resulting regression is as follows:

For unconfined compressive strength:

$$
\begin{aligned}
& U C S=-6.045+7.685 C_{C}+0.713 T \quad\left[R^{2}=0.971\right] \\
& U C S=-108.468+7.607 C_{C}+0.674 T+47.656 D_{D} \quad\left[R^{2}=0.976\right]
\end{aligned}
$$

For modulus of elasticity:

$$
\begin{aligned}
& E S=-1298.470+1467.375 C_{C}+131.584 T \quad\left[R^{2}=0.974\right] \\
& E S=-1873.914+1466.938 C_{C}+131.367 T+267.747 D_{D} \quad\left[R^{2}=0.974\right]
\end{aligned}
$$

where, unconfined compressive strength (UCS) unit: $\mathrm{kg} / \mathrm{cm}^{2}$, cement content $\left(\mathrm{C}_{\mathrm{C}}\right)$ unit: $\%$ by weight, curing time $(T)$ unit: days, dry density $\left(D_{D}\right)$ unit: ton $/ \mathrm{m}^{3}$, modulus of elasticity $(E S)$ unit: $\mathrm{kg} / \mathrm{cm}^{2}$.

It should be noted that the modulus of elasticity in this study represents the modulus of elasticity at $50 \%$ of ultimate load. To determine the static modulus of elasticity, the slope based on the two linear points of stress-strain relation: 1) the first point at longitudinal strain $50 \mu \varepsilon$ and 2) the second point at compressive stress corresponding to $50 \%$ of ultimate load was used for this purpose. Comparison between the experimental data and predicted values obtained from Eq. (4) and Eq. (6) were presented in Fig. 6. The maximum absolute error percentage of unconfined compressive strength and modulus of elasticity were found to be 11 and $12 \%$, respectively. 
At low cement contents ductile stress-strain relationships were observed though brittle behavior appeared with increasing strength. The modulus of elasticity of the lateritic soil-cement also increases with increasing strength. Approximate ratios of the elastic modulus to unconfined compressive strength of cement treated lateritic soils varied between 100 and 200. Therefore unconfined compressive strength and the modulus of elasticity can be stated by Eq. (4) and Eq. (6), respectively. In addition, the relationship between the modulus of elasticity and unconfined compressive strength tend to from the linear model as given in Eq. (7).

$$
E S=-71.83+188.28 U C S \quad\left[R^{2}=0.984\right]
$$

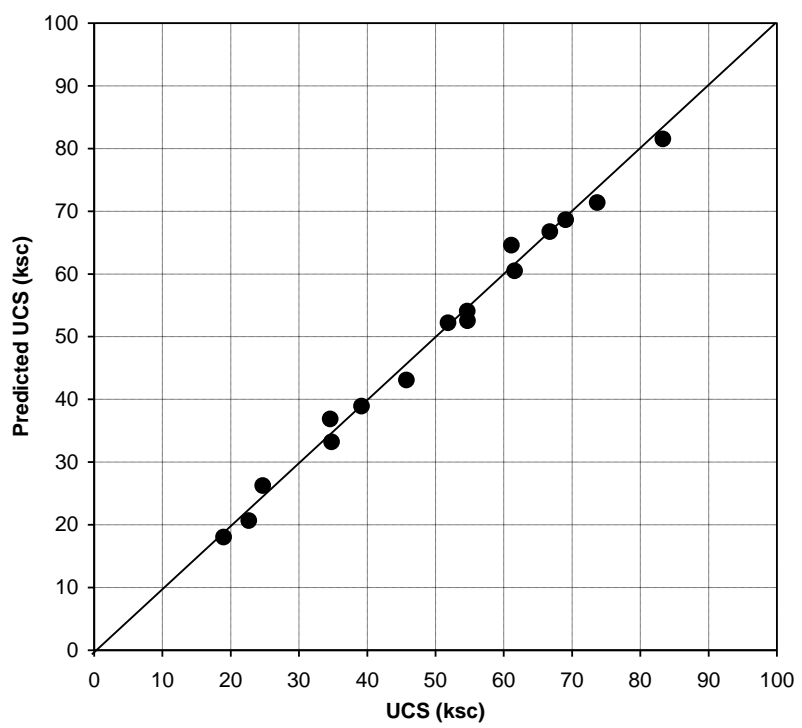

(a) Unconfined compressive strength.

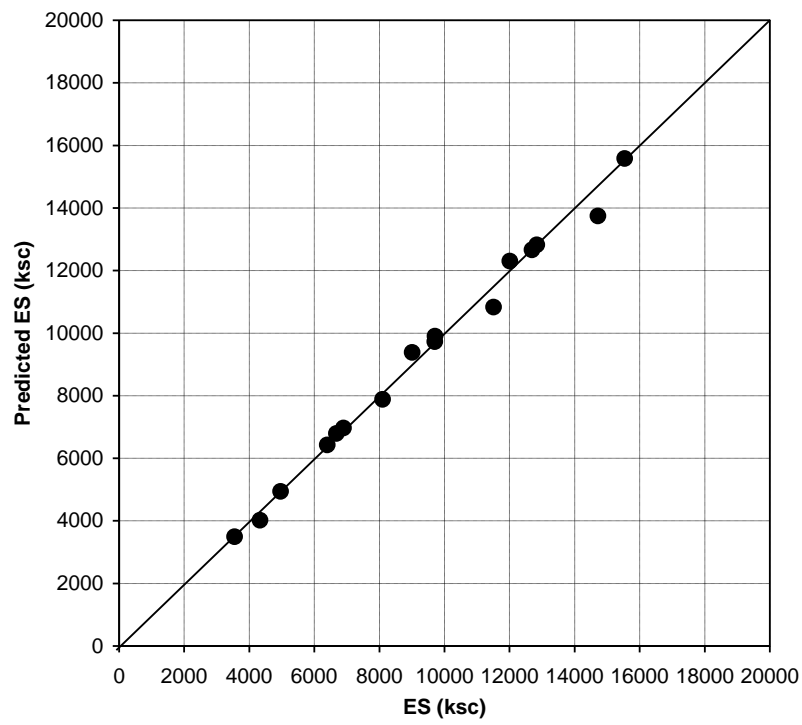

(b) Modulus of elasticity.

Fig. 6. Comparison of Experimental data and predicted values.

\section{Conclusions}

The improved strength of the lateritic soil-cement depends on many factors such as the type of soils, cement content, water content ratio and curing time. The strength increases proportionally with increasing cement content. The strength increased about $10 \mathrm{ksc}$ for every $2 \%$ increase in cement content. The average 
ES/UCS ratio is about 200 regardless of the cement content. The strength of soil-cement increases linearly with the logarithmic of time. The optimum curing time for soil-cement mixing is 14 days. The strength at 7 days varies from 1.11 to 1.17 of the 3 days strength with an average value of 1.14 . There is an overall improvement in the strength characteristics of the lateritic soil and this behavior has been confirmed from unconfined compression tests. This can be realized with increase in the induced UCS and ES values. There is an increase in the strength of the lateritic soil by about 4 times for $5 \%$ cement weight by soil weight when compared to the untreated soil. Based on the results of the study, the following conclusions can be drawn:

- Multiple regression models can be used to predict the strength and modulus of lateritic soil-cement more easily and efficiently since it is more user-friendly.

- The higher the percentage of cement added the higher the increment in the strength and modulus of treated soil.

- Unconfined compressive strength and modulus of elasticity (ES) are improved significantly as the cement content is increased.

- Cement content (CC) and curing time (T) have major effects on the strength and modulus of lateritic soil-cement in flexible pavement.

- On the basis of the results, $3 \%$ cement content is the optimum for use as a base course in highway pavements.

- The performance evaluations showed that the multiple regression model predictions are very satisfactory in estimating unconfined compressive strength and modulus of elasticity.

\section{References}

[1] T. Ruenkrairergsa, "Design, construction, and performance of silty sand stabilized road base," Proc. 7th ARC Soil Mechanics and Foundations, vol. 1, pp. 136-143, 1983.

[2] T. Ruenkrairergsa, "Development of soil cement road in Thailand," Proc. 11th IRF World Meeting, 1989.

[3] T. Ruenkrairergsa, and A. Thaweewonsodsai, "Stress-strain characteristics of cement treated materials under unconfined compression test," RD. 179, Road Research and Development Center, Department of Highways, Thailand, 2000.

[4] T. Ruenkrairergsa, and S. Jaratkorn, "Unconfined compressive strength of soil-cement under various density," RD. 188, Road Research and Development Center, Department of Highways, Thailand, 2001.

[5] A. M. Neville, and J. J. Brooks, Concrete Technol., Longman Scientific \& Technical, 1987.

[6] P. T. Sherwood, "The stabilization with cement of weathered and sulphate-bearingclays," Geotechnique, vol. 7, no. 4, pp. 179-191, 1957.

[7] Anon., "State-of art report on soil-cement," Am. Conc. Inst. Mater. J., vol. 87 no. 4, pp. 395-417, 1990.

[8] T. Kawasake, A. Niina, S. Saitoh, Y. Suzuki, and R. Babasaki, "Deep mixing method using cement slurry as hardening agent," Proc. Seminar on Soil Improvement and Construction Techniques in Soft Ground, Singapore, pp. 17-38, 1984.

[9] A. Z. Baghadadi, and A. M. Khan, "A study of use of sea water in lime and cement stabilization," Proc. Symposium on Environmental Geotechnics and Problematic Soils and Rocks, Bangkok, Thailand, pp. 139-144, 1985.

[10] H. F. Winterkorn, and H. Y. Fang, Foundation Engineering Handbook, 2nd ed., Van Nostrand Reinhold, New York, 1991.

[11] J. K. Mitchell, "Soil improvement: State-of-the-art," Proc. 10th International Conference on Soil Mechanics and Foundation Engineering, Stockholm, Sweden, vol. 4, pp. 509-565, 1981.

[12] F. G. Bell, Engineering Treatment of Soil: Soil Stabilization, UK: Taylor \& Francis, 1993.

[13] D. T. Bergado, T., Ruenkrairergsa, Y. Taesiri, and A. S. Balasubramainam, "Deep soil mixing to reduce embankment settlement," Ground Improvement, vol. 3, no. 3, pp. 145-162, 1999.

[14] N. R. Draper, and H. Smith, Applied Regression Analysis, New York: John Wiley \& Sons, 1998. 
